\title{
Production Analysis of Multi-Stage Hydraulically Fractured Horizontal Wells in Tight Gas Reservoirs
}

\author{
Fei Wang ${ }^{1} \&$ Shicheng Zhang $^{1}$ \\ ${ }^{1}$ School of Petroleum Engineering, China University of Petroleum, Beijing, China \\ Correspondence: Fei Wang, Petroleum Engineering, China University of Petroleum, Beijing, No.18, FuXue Road, \\ China. Tel: 86-010-8973-4593. E-mail: wangfei@cup.edu.cn
}

Received: September 1, 2014

doi:10.5539/jgg.v6n4p58

The research is financed by the Science Foundation of China University of Petroleum, Beijing (No.YJRC-2011-02).

\begin{abstract}
Activities in exploitation and developing tight gas reservoirs grown tremendously in recent years. The horizontal well with multi-stage hydraulic fracture stimulation has proven to be an effective strategy of developing these unconventional resources. However, to evaluate the fracturing treatment and predict the long-term production behavior of wells in gas recovery it is important to estimate the effective half-length and spacing of created hydraulic fractures and the extent of the stimulated reservoir volume (SRV). In this paper, a simplified linear model is presented to represent the relationship between fractures and matrix rock. Four flow regimes are identified with this model which exhibits the production dynamics of multi-stage fractured horizontal wells (MFHW). Rate-normalized gas pseudopressure is derived from production data and used to interpret flow regimes with corresponding calculation equations. We illustrate the analysis procedure with two field cases from a tight gas reservoir in Northeast China. The results prove that the proposed method works well in analyzing production data from tight gas wells in their early life. The potential in further developing this technique for practical application is obvious and looks very promising.
\end{abstract}

Keywords: production analysis, multi-stage hydraulically fractured horizontal wells, tight gas reservoirs, flow regime, fracturing evaluation

\section{Introduction}

Tight gas sand reservoirs are widely distributed in China (Li shilun et al, 2002). Formations in tight sand are characterized by low porosity, low permeability and even complicated natural fractures. Traditional stimulation and fracturing technology cannot realize effective production. With the success in developing unconventional gas resources in the United States, the horizontal well with multi-stage hydraulic fracture stimulation (MFHW) has proven to be an effective way for extraction of hydrocarbon from tight formations economically. Various analytical, semi-analytical and empirical models have been developed to study MFHW pressure/rate behavior. Larsen and Hegre (1991 and 1994) studied pressure transient behavior of the MFHW and provided description of pressure-transient flow regimes with corresponding analytical solutions. Al-Kobashi et al (2006) concentrated on the pressure-transient characteristics at the early-time flow regimes. They described the fracture storage induced flow regimes for the MFHW including fracture-radial, radial-linear flow and bilinear linear flow. In their literatures, the early time corresponding to the period prior to the start of the interference between fractures were considered. Since the fracture interference is negligible, the pressure response of the MFHW was correlated with the single fracture responses. Zerzar et al (2004) and Clarkson et al (2009) concentrated on the pressure-transient characteristics at relatively later times (after the end of fracture-storage). They described flow regimes for the MFHW including pseudo-linear flow, pseudo-radial and bi-radial (compound linear) flow before infinite-acting. Bello and Wattenbarger (2010) described the rate transient behavior of the MFHW and identified five flow regions that may exhibit throughout its production life. Quasi-steady state flow was identified by Cheng (2011) through numerical simulation. This term was introduced also as pseudo pseudosteady state for the flow regime between pseudolinear flow and compound linear flow. 
Methods of analyzing production data were investigated by different authors. Lewis and Hughes (2008) presented type-curves for single and dual-porosity gas reservoirs using a modified material balance time. Medeiros et al (2008) presented a semi-analytical solution for the MFHW. Jordan et al (2009) presented a trial and error method to match production data and estimate original gas in place and other parameters using semi-analytic quadratic rate-cumulative production related. Kupchenko et al (2008) summarized the behavior of the decline exponent in single fractured wells and proposed a method for applying traditional decline-curve analysis to tight gas. Luo et al (2010) applied reciprocal rate derivative plot to identified and analyze flow regimes of the MFHW producing under constant bottomhole pressure. Song et al (2011) applied rate-normalized pressure analysis to determination of shale gas well performance.

The objective of this paper is to develop a methodology to conduct proper analysis of MFHW flow regimes in tight gas formations. Based on the current situations, the hydraulically fractured horizontal tight gas well will be modeled as a horizontal well draining a rectangular geometry containing a system of fractures with matrix blocks (dual-porosity system). The transient linear solutions for single vertical fractured wells will be modified and extended to this system. Rate-normalized pseudopressure, $\mathrm{m}(\mathrm{RNP})$ derived from production data will be used for analysis reasonably since this converted form solves the gas diffusion and rate variation effects. Key parameters of fracturing treatment evaluation, i.e. average effective half-length and spacing of created hydraulic fractures, the extent and gas recovery of SRV will be calculated.

\section{Physical Model and Assumptions}

A multi-stage fractured horizontal tight gas well can be considered as producing from a rectangular dual-porosity reservoir, namely a system of fractures with matrix blocks, sketched in Figure1. A stimulated reservoir volume (SRV) is created by hydraulic fractures and adjacent stimulated zone. The matrix blocks are assumed to be homogeneous and may exhibit simple anisotropy. Hydraulic fractures emanate from perforation clusters in the wellbore. It is assumed that the perforation clusters are equally spaced and each fracture has same properties, i.e. length, width, height and permeability are identical. Gas flows through fractures and toward the well at the centre of the rectangular geometry. The main advantage of this model is that the reservoir extends beyond the fracture system, which allows complete flow dynamics. While within the early-time linear flow, the fractures do not drain beyond the boundaries of the SRV.

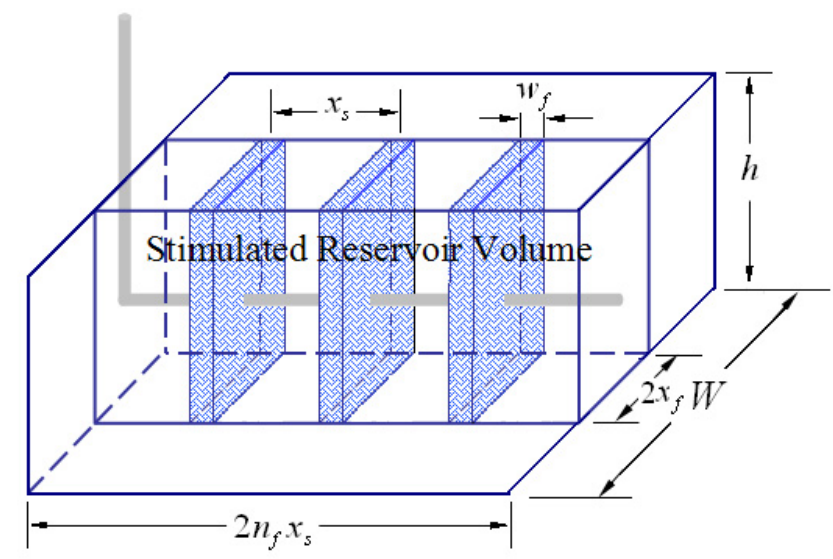

Figure 1. a MFHW in a conventional tight gas formation

\section{Flow Regimes}

For the physical model considered here, in the absence of wellbore storage effects, four major flow regimes to control the well production dynamics are expected as follows (sketched in Figure 2):

(a) Fracture-storage induced flow regime. During this flow regime, the flow in fracture dominates while the flow into the fracture from the formation is insignificant (Figure 2a). It may be fracture-radial, radial-linear, or bilinear flow (Larsen and Hegre, 1994). The flow type heavily depends on the fracture geometry (Al-Kobashi, 2005);

(b)Fracture inner boundary dominated flow. During this flow regime, gas flows down the fracture and flow in the reservoir is normal to the fracture planes. Flow across the fracture tips is negligible and each fracture behaves independently of the other fracture (Figure2b); 


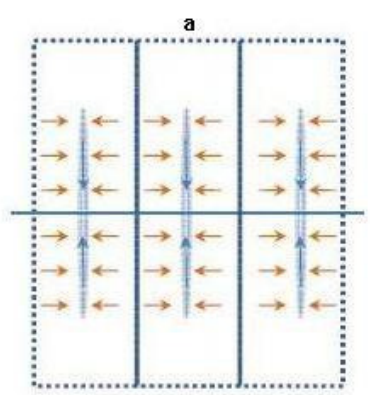

Fracture-storage induced flow

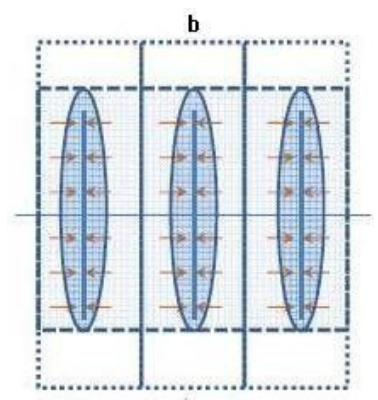

Fracture inner linear flow

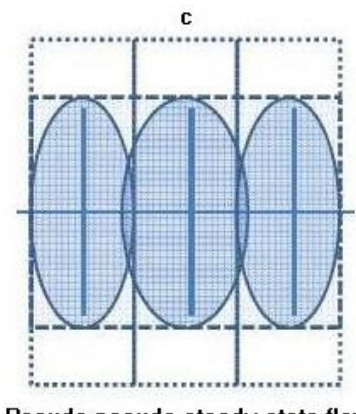

Pseudo pseudo-steady state flow

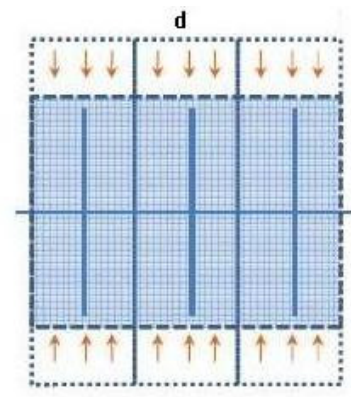

Fracture system outer flow

Figure 2. Flow regimes of a MFHW

(c) Fracture interference dominated flow. During this flow regime, pressure interference between adjacent fractures dominates while the flow across the boundary between the inner and the outer reservoir starts but is insignificant (Figure 2c). In the case of the fracture spacing which is less than its half length, it is an approximate quasi-steady state flow or pseudo-steady state flow(Song, 2011), with which the inner reservoir is depleting with limited contribution from the outer reservoir.

(d) Fracture system (fracture outer boundary) dominated flow. During this regime, fracture interacts. The composite fracture system behaves as if it were a single fracture with a volume equal to the SRV (Figure 2d). It may consist of compound linear flow, compound pseudoradial flow, and boundary behavior, depending on the reservoir geometry.

Figure 3 shows these flow regimes on log-log plot of rate-normalized pseudopressure and its derivative versus time. It appears that bilinear flow regime exhibits a 0.25 slope line followed by a 0.5 slope linear flow regime on derivative responses, while pseudo pseudo-steady state flow exhibits 0.88 slope on derivative responses. Then compound linear flow and pseudo steady state exhibit 0.5 slope and 1 slope on derivative responses in succession. The state among the four flow regimes is known as transition zone in well test analysis, which won't display straight line slope on log-log diagnostic plot. The flow regimes presented above may not exist in a single test. Depending on the specific properties of the fracture and reservoir, some of the flow regimes may be absent. For the moderate ratios of fracture length and $\operatorname{spacing}\left(\mathrm{x}_{\mathrm{f}} / \mathrm{x}_{\mathrm{s}}=1 / 4\right)$, the pseudo pseudo-steady state flow regime may be nonexistent or replaced by a transitional period ,called middle-radial flow(Wang et al, 2014).

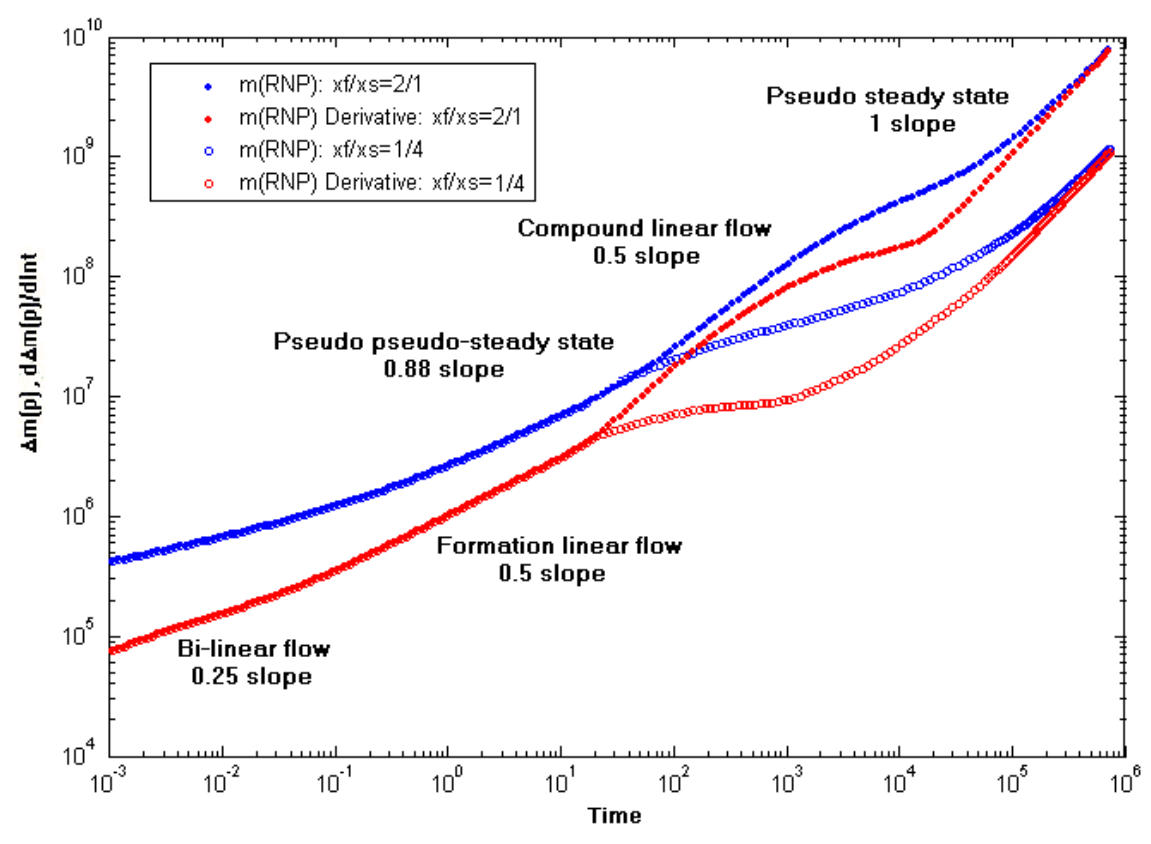

Figure 3. Log-log diagnostic plot of a MFHW(Simulation with ECLIPSE) 


\section{Rate-Normalized Pseudopressure Analysis}

The general solution for the wellbore flowing pressure in a reservoir is expressed in terms of dimensionless variables. For fractured gas wells, it is given by (Cinco-Ley et al, 1978)

$$
p_{w D}\left(t_{D x_{f}}, C_{F D}\right)=\frac{k h\left[m\left(p_{i}\right)-m\left(p_{w f}\right)\right]}{1424 q_{g} T}
$$

Where

$$
\begin{aligned}
& t_{D x_{f}}=\frac{2.637 \times 10^{-4} k t}{\phi \mu_{g} c_{t} x_{f}^{2}} \\
& C_{F D}=\left(k_{f} w_{f}\right)_{D}=\frac{k_{f} w_{f}}{k x_{f}}
\end{aligned}
$$

$p_{w D}$ represents the dimensionless pressure drop. It is a function of dimensionless time, $t_{D x_{f}}$ and dimensionless fracture conductivity $C_{F D}$. When $C_{F D}$ is greater than 300 , which means infinite conductive fractures, the formation linear flow is exhibited rather than bilinear flow. During the formation linear flow period, the dimensionless pressure response at the wellbore is given by

$$
p_{w D}=\sqrt{\pi t_{D x_{f}}}
$$

For gas reservoirs, pressure transient responses need to be analyzed in terms of pseudopressure. The pseudopressure is conventionally defined by (Al-Hussainy et al, 1966):

$$
m(p)=\int_{0}^{p} \frac{2 p}{\mu_{g} Z} d p
$$

For multiple fractures along the horizontal drain, we consider a equivalent fracture. Its half length, $X_{f}$ would be the sum of the individual fractures half lengths. Hence, the pressure response at the wellbore for linear transient flow from matrix blocks to fractures can be expressed as

$$
m\left(p_{w f}\right)=m\left(p_{i}\right)-\frac{40.925 q_{g} T}{h_{f} X_{f}} \sqrt{\frac{t}{k \phi \mu_{g} c_{t}}}
$$

Where

$$
X_{f}=n \bar{x}_{f}
$$

This equation indicates that a $\log \log$ graph of $\left[m\left(p_{i}\right)-m\left(p_{w f}\right)\right\rfloor / q_{g}$ vs. time yields a straight line whose slope is equal to one half. A graph of $\left[m\left(p_{i}\right)-m\left(p_{w f}\right)\right\rfloor / q_{g}$ vs. The square root of time also gives a straight line whose slope $m_{l f}$ is inversely proportional to the fracture number, fracture height and the average fracture half length. The fracture product $n h_{f} \bar{x}_{f}$ can be calculated for the slope as follows:

$$
n h_{f} \bar{x}_{f}=\frac{40.925 T}{m_{l f}} \sqrt{\frac{1}{k \varphi \mu c_{t}}}
$$

The investigation equation for pseudolinear flow is given by (Ehlig-Economids, 1992)

$$
r_{i}=4 \sqrt{\frac{0.0002637 k_{x} t}{\phi \mu_{g} c_{t}}}
$$


For an infinite conductivity fracture, the apparent end of pseudolinear flow is given by (Gringarten et al, 1974)

$$
t_{D x_{f}} \cong 0.016
$$

For isotropic formation, $k_{x}=k_{y}=k$, substituting Eq.(10) and Eq.(2) into Eq.(9) provides that

$$
r_{i}=4 x_{f} \sqrt{0.016}=x_{f} / 2
$$

For multiple fractures along the horizontal drain, so if $r_{i}=\bar{x}_{s} / 2 \leq \bar{x}_{f} / 2$, the time at the end of the linear flow occurs when flow to adjacent fractures interferes. With Eq.(9), the occurrence time is equal to

$$
t_{\text {eplf }}=\frac{\phi \mu_{g} c_{t}\left(\bar{x}_{s} / 2\right)^{2}}{4^{2} \times 0.0002637 k}=\frac{948 \phi \mu_{g} c_{t} \bar{x}_{s}^{2}}{16 k}
$$

Inversely average fracture spacing can be calculated if the end time of linear flow known. If $\bar{x}_{s}>\bar{x}_{f}$, when $t_{D x_{f}}>0.016$, we cannot use Eq.(12) to calculate the time at the end of the linear flow. In this situation, pseudo pseudo-steady state period won't exhibit and may be replaced by a bi-radial flow (Zerzar et al, 2004). We won't discuss this situation in this paper.

Then the pore volume of SRV can be approximated to

$$
V_{p}=2 n_{f} \bar{x}_{s} \bar{x}_{f} h_{f} \phi
$$

This gives a direct method of estimating OGIP in SRV as follows

$$
O G I P_{s r v}=\frac{V_{p} S_{g}}{B_{g}}
$$

The value of $V_{p}$ provides useful information in evaluating well's fracturing treatment effectiveness. $O G I P_{s r v}$ reflects well's production potential under the current fracturing simulation condition.

Based on the derivation and modification of mathematical model above, rate-normalized pseudopressure analysis method, which can solve rate variations and represent the production behavior, is proposed to interpret MFHW flow regimes with corresponding calculation of fracture parameters. The rate-normalized pseudopressure drop, its derivative and material balance time are defined as:

$$
\begin{gathered}
m(R N P)=\frac{m\left(p_{i}\right)-m\left(p_{w f}\right)}{q_{g}} \\
m\left(R N P^{\prime}\right)=\frac{d m(R N P)}{d \ln (t)} \\
t_{e}=Q(t) / q_{g}(t)
\end{gathered}
$$

The procedure of $\mathrm{m}(\mathrm{RNP})$ analysis can be summarized as follows:

a) Obtain field production data.

b) Calculate m(RNP) and m(RNP)' with the production data using Eq.(15) and Eq.(16) and put them on log-log plot against material balance time. Check for the half slope and almost unit slope on m(RNP)' response indicating the early-time linear flow and pseudo pseudo-steady state flow regimes. Determine the occurrence time of fracture interference $t_{e p l f}$ and using Eq.(12) to calculate average fracture spacing $x_{s}$.

c) Check for a straight line on a plot of $\mathrm{m}(\mathrm{RNP})$ against $t_{e}^{0.5}$. Draw a line through the origin on the plot of 
$\mathrm{m}(\mathrm{RNP})$ against $t_{e}^{0.5}$ passing through the linear half-slope data points. Determine the slope of this line. It will be designated as $m_{l f}$ and used in Eq.(8) to calculate average fracture half-length $x_{f}$.

d) If matrix porosity $\varphi$, saturation $S_{g}$ and volume factor $B_{g}$ are known, the calculate pore volume of SRV and the OGIP in SRV using Eq.(13) and Eq.(14).

e) Use these values calculated above to build a numerical model and yield a series of flow rate and cumulative rate values based on the real pressure history. Fit the numerical solution with the real production history.

\section{Field Examples}

Two field examples from a tight sandstone reservoir in Northeast China illustrates the application of the rate-normalized pseudopressure production data analysis. Table 1 shows the fluid and formation data of this field. Well47 and Well56 are multiple fractured horizontal wells in this field. Well completion parameters of these two wells are shown in Table 2. In these two examples, casing pressure was recorded on at least a daily basis. Because the production is predominantly single-phase gas, the casing pressure trends mimic the bottomhole pressure closely. So the casing pressure and flow rate data will be used for the following production analysis.

Table 1. Fluid and formation data of the field

\begin{tabular}{ll}
\hline Parameter & Value \\
\hline Initial reservoir pressure, pi & $28.46 \mathrm{MPa}$ \\
Reservoir depth, d & $3290 \mathrm{~m}$ \\
Total compressibility, ct & $2.2 \times 10^{-4} \mathrm{psi}^{-1}$ \\
Matrix porosity, $\varphi$ & 0.09 \\
Matrix permeability estimates, $\mathrm{k}$ & $7.8 \times 10^{-4} \mathrm{md}$ \\
Initial gas viscosity, & $0.019 \mathrm{cp}$ \\
Reservoir temperate, $\mathrm{T}$ & $104{ }^{\circ} \mathrm{C}$ \\
Formation thickness, $\mathrm{h}$ & $35 \mathrm{~m}$ \\
\hline
\end{tabular}

Table 2. Well completion parameters of Well47 and Well56

\begin{tabular}{ll}
\hline Parameter & Value \\
\hline Well spacing, $\mathrm{W}$ & $600 \mathrm{~m}$ \\
Well47 horizontal well length, $\mathrm{L}_{1}$ & $805 \mathrm{~m}$ \\
Well56 horizontal well length, $\mathrm{L}_{2}$ & $1256 \mathrm{~m}$ \\
Well47 total number of fractures, $\mathrm{n}_{\mathrm{f} 1}$ & 4 \\
Well56 total number of fractures, $\mathrm{n}_{\mathrm{f} 2}$ & 8 \\
\hline
\end{tabular}

Figure 4 shows the production history of Well47 and Figure5 shows the m(RNP) and m(RNP)'on log-log plot. Due to the wellbore storage effect, the early-time linear flow behavior was masked that the derivative response deviates from the half-slope line. Several days later, the formation linear flow exhibits indicated by a half-slope trend and followed by a pseudo pseudo-steady state flow indicated by a 0.88 slope trend in the diagnostic plot. The end point of linear flow, $t_{\text {eplf }}$ is about 200 day. Using Eq.(12)and the data in Table 1, the average fracture spacing $x_{s}$ can be calculated as $113.5 \mathrm{~m}$. 


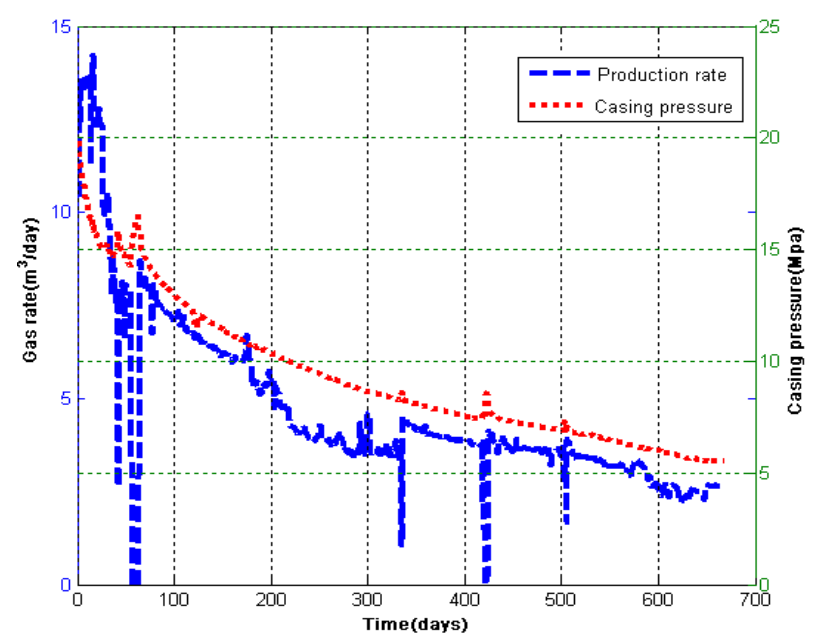

Figure 4. Production history of Well 47

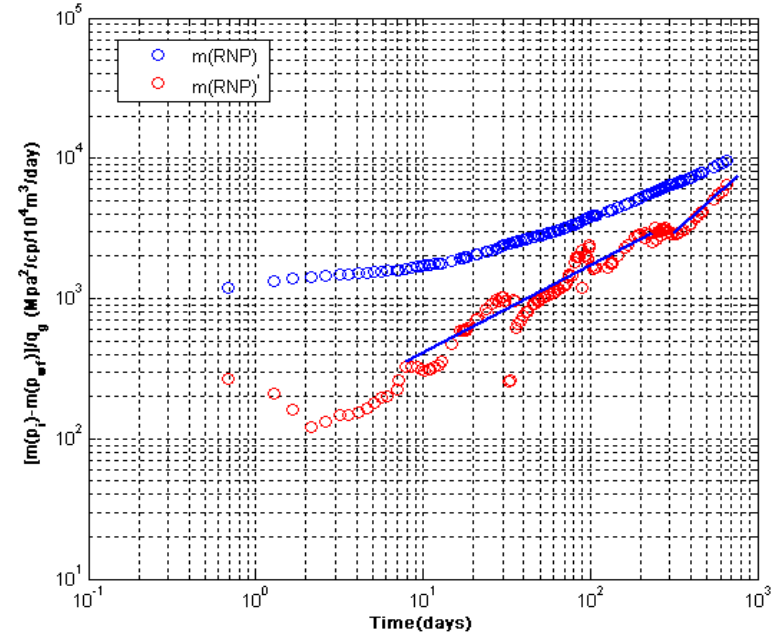

Figure 5. Log-log diagnostic plot of Well 47

Figure6 shows specialized plot of them(RNP) against the square-root-of-time. The slope of the line drawn through the origin inFigure6 is determined as $m_{l f}=4.42 * 10^{6} \mathrm{Mpa}^{2}$ day ${ }^{0.5} \mathrm{cp}^{-1}\left(\mathrm{~m}^{3}\right)^{-1}$. Using Eq. (8) with the data in Table 1, the average fracture half-length is calculated as $x_{f}=204 \mathrm{~m}$. Then using Eq.(13) the simulated pore volume can be calculated as $V_{p}=5.84 \times 10^{5} \mathrm{~m}^{3}$. The OGIP in SRV can be also estimated with a given gas saturation and formation volume factor using Eq.(14).

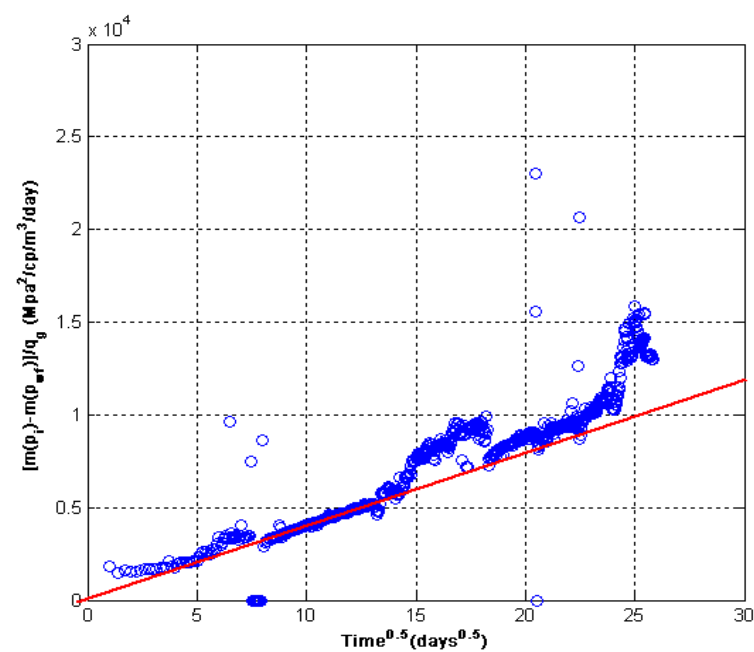

Figure 6. Square-root-of-time plot of Well 47

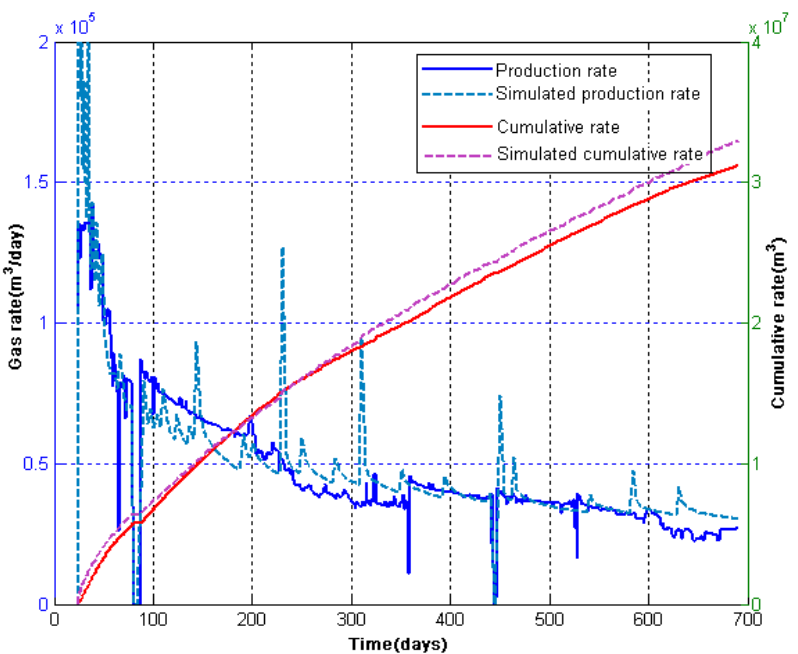

Figure 7. Well 47 production rate and cumulative data match

According the completion parameters in Table 2, a numerical model has been constructed for history match the production of well 47 . The rectangular boundary is set to $600 \mathrm{~m} \times 805 \mathrm{~m}$. 4 transverse fractures along the horizontal drain is equally spaced. The fracture spacing and half-length values calculated above are inputted to the numerical model. Other input parameters are from the list in Table1. Figure 7shows the match for production rate and cumulative production data using values for $x_{f}$ and $x_{s}$ estimated above. Obviously, the simulated solutions which derived from a numerical MFHW model are consistent with the real production history and further prove the proposed analysis method.

Figure 8 shows the production history of Well56 and Figure9 shows the rate-normalized pseudopressure and its derivative on log-log plot. The diagnostic plot shows both linear flow indicated by a half-slope trend and pseudo pseudo-steady state flow indicated by a 0.88 slope trend in the rate-normalized pseudopressure derivative. Water flow back was noted during the clean-up and the first dozens of hours of the production. With the end point of linear flow, $t_{\text {eplf }}=190$ day, using Eq.(12) and the data in Table1, the average fracture spacing $x_{s}$ can be calculated as $110 \mathrm{~m}$. 


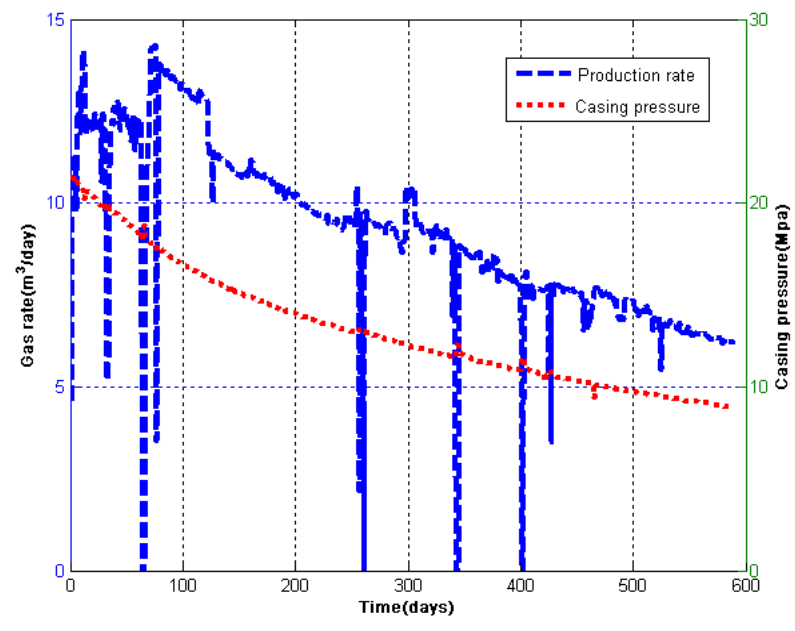

Figure 8. Production history of Well 56

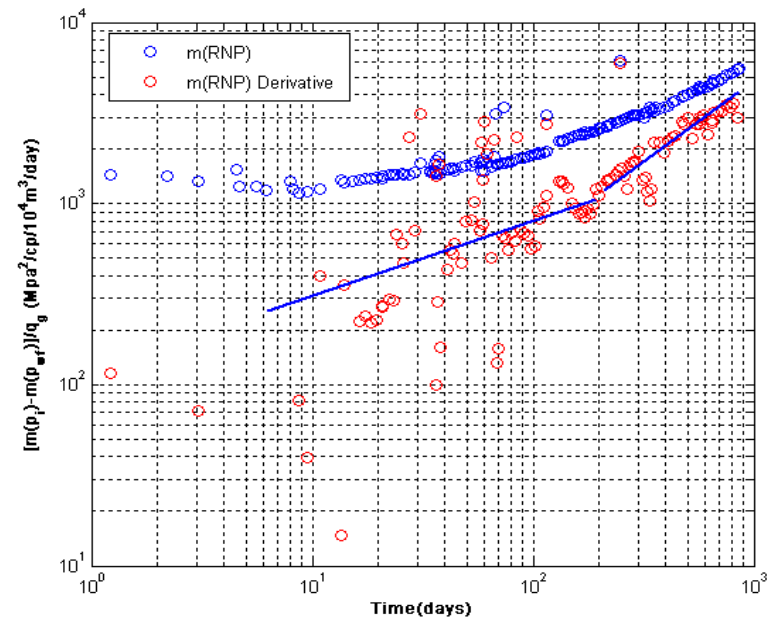

Figure 9. Log-log diagnostic plot of Well 56

Figure10 shows specialized plot of the rate-normalized pseudopressure against the square-root-of-time. The slope of the line drawn through the origin in Figure10 is determined as $m_{l f}=2.31 * 10^{6} \mathrm{Mpa}^{2} \mathrm{day}^{0.5} \mathrm{cp}^{-1}\left(\mathrm{~m}^{3}\right)^{-1}$. Using Eq.(8) with the data in Table 1, the average fracture half-length is calculated to be $210 \mathrm{~m}$. Then using Eq.(13)the simulated pore volume can be calculated as $1.21 * 10^{6} \mathrm{~m}^{3 .}$ The OGIP in SRV can be also estimated with a given gas saturation and formation volume factor using Eq.(14).

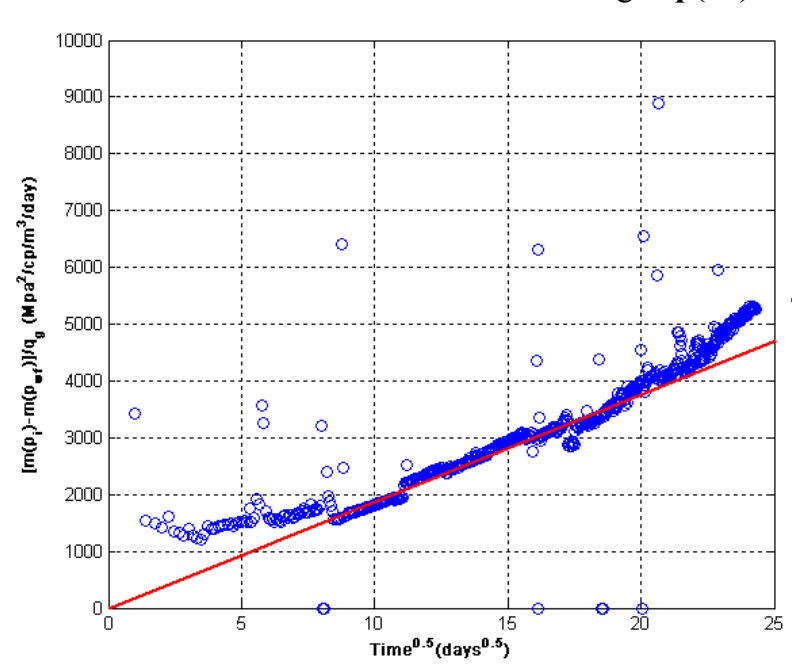

Figure 10. Square-root-of-time plot of Well56

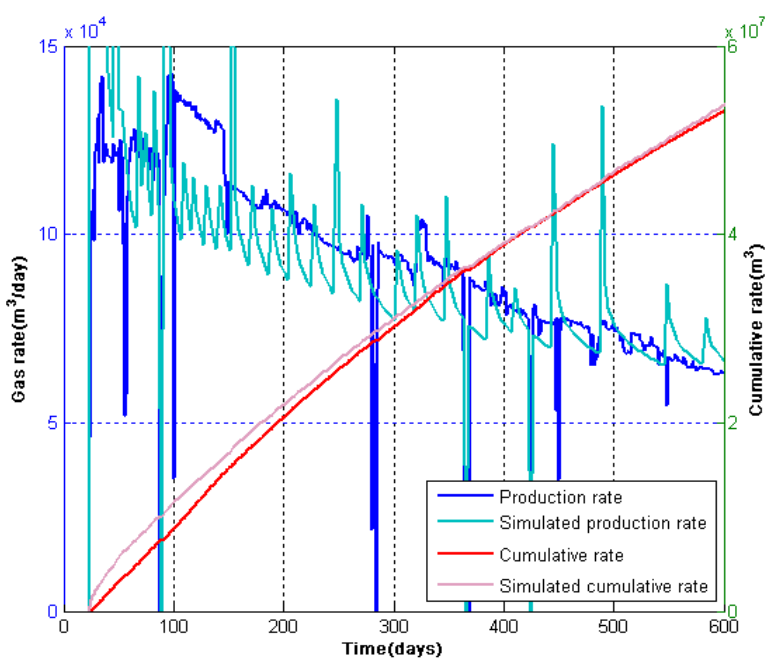

Figure 11. Well56 production rate and cumulative data match

According the reservoir parameters in Table1 and completion parameters in Table $\mathbf{2}$, a numerical model has been constructed for history match the production of Well56. The rectangular boundary is set to $600 \mathrm{~m} \times 1256 \mathrm{~m}$. 8 transverse fractures_along the horizontal drain is equally spaced. The fracture spacing and half-length values calculated above, $x_{f}=210 \mathrm{~m}$ and $x_{s}=110 \mathrm{~m}$ are inputted to the numerical model. Figure 11shows the match for production rate and cumulative production data. Obviously, the simulated solutions which derived from a numerical MFHW model are consistent with the real production history and further prove the proposed analysis method. In summary, the analysis for Well47and Well56 provides the average fracture half-length, effective spacing of adjacent fractures, simulated pore volume and the OGIP in SRV.

\section{Conclusions}

In this paper, we have studied the pressure transient behavior of multiple infinite-conductivity transverse fractures intercepted by a horizontal well. Five basic flow regimes of a MFHW have been identified by simulated pressure derivative on log-log plot. Bilinear flow regime exhibits 0.25 and linear flow regime exhibits 0.5 slope on derivative responses, while pseudo pseudo-steady state flow exhibits 0.88 slope on derivative 
responses. Then compound linear and pseudo-steady state flow exhibit 0.5 slope and 1 slope on derivative responses in succession. We also presented a methodology to analyze long-term production data of multi-stage hydraulically fractured horizontal tight gas wells using a modified linear flow model and two rate-normalized gas pseudopressure plots, i.e. log-log diagnostic plot and square-root-of-time specialized plot.

We demonstrated the applicability of our methodology with field examples from a tight sandstone reservoir in Northeast China. Early-time linear flow and pseudo pseudo-steady state flow regimes were identified in field data which enables estimation of the average fracture half-length, effective fracture spacing, simulated pore volume and the OGIP in SRV. The matching results with numerical models proved that our analysis method works well in practice and provides useful information in evaluation of well's fracturing treatment effectiveness and production potential.

\section{Acknowledgments}

The authors would like to thank Science Foundation of China University of Petroleum, Beijing (No.YJRC-2011-02) for the financial support during this research.

\section{References}

Al-Hussainy, R., Ramey, Jr., H. J., \& E Crawford, P. B. (1966). The Flow of Real Gases Through Porous Media. JPT186, (5), 624-636.

Al-Kobaisi, M., Ozkan, E., Kasogi, H., \& Ramirez, B. (2006). Pressure-Transient Analysis of Horizontal Wells with Transverse, Finite-conductivity Fractures. Paper PETSOC 2006-126 presented at the Petroleum Society's 7th Canadian International Petroleum Conference (57th Annual Technical Meeting). Calgary, Alberta, Canada, 13-15.

Al-Kobashi, M. (2005). Pressure-Transient Response of a Finite-Conductivity Fracture Intercepted by a Horizontal Well; MSc Thesis, Colorado School of Mines, Golden, CO.

Bello, R. O., \& Wattenbarger, R. A. (2010). Multi-stage Hydraulically Fractured Shale Gas Rate Transient Analysis. Paper SPE 126754 presented at the SPE North Africa Gas Technical Conference and Exhibition. Cairo, Egypt, 14-17.

Cheng, Y. M. (2011). Pressure Transient Characteristics of Hydraulically Fractured Horizontal Shale Gas Wells. Paper SPE 149331 presented at the SPE Eastern Regional Meeting. Columbus, Ohio, 17-19.

Cinco, L., H., \& Samaniego, V. F. (1978). And Dominguez N. Transient Pressure Behavior for a Well with Finite Conductivity Vertical Fracture. Soc. Pet. Eng. J., 8, 253-264. http://dx.doi.org/10.2118/6014-PA

Clarkson, C. R., Jordan, C. L., Ilk, D., \& Blasingame, T. A. (2009). Production Data Analysis of Fractured and Horizontal CMB Wells. Paper SPE 125929 presented at the 2009 SPE Eastern Regional Meeting. Charleston, West Virginia, 23-25.

Ehlig-Economides, C. A. (1992). Computation of Test Area of Investigation in Nonradial Geometries. SPE 25020, presented at the European Petroleum Conference. Cannes, France, Nov. 16-18. http://dx.doi.org/10.2118/25020-MS

Gringarten, A. C., \& Ramey, H. J. (1974). Jr. Unsteady State Pressure Distributions Created by a Well with a Single-Infinite Conductivity Vertical Fracture. Soc. Pet. Eng. J., 8, 347-360. Trans. AIME, Vol. 257. http://dx.doi.org/10.2118/4051-PA

Ibrahim, M., \& Wattenbarger, R. A. (2005). Analysis of Rate Dependence in Transient Linear Flow in Tight Gas Wells. Paper CIPC2005-057 presented at the Canadian International Petroleum Conference. Calgary, Alberta, 7-9.

Jordan, C. L., Smith, C. R., \& Jackson, R. A. (2009). Rapid \& Efficient Production Analysis Method for Unconventional and Conventional Gas Reservoirs. Paper SPE 120737 presented at the 2009 Asia Pacific Oil and Gas Conference and Exhibition. Jakarta, Indonesia, 4 - 6.

Kupchenko, C. L., Gault, B. W., \& Mattar, L. (2008). Tight Gas Production Performance Using Decline Curves. Paper SPE 114991 presented at the CIPC/SPE Gas Technology Symposium 2008 Joint Conference. Calgary, Alberta, 16 - 19.

Larsen, L., \& Hegre, T. M. (1991). Pressure-Transient Behavior of Horizontal Wells with Finite-Conductivity Fractures; SPE 22076, presented at the SPE International Arctic Conference. Anchorage, AK, May 29-31. $\mathrm{http}: / / \mathrm{dx}$.doi.org/10.2118/22076-MS 
Larsen, L., \& Hegre, T. M. (1994). Pressure Transient Analysis of Multifractured Horizontal Wells; SPE 28389, presented at the SPE Annual echnical Conference and Exhibition. New Orleans, LA, Sept. 25-28. http://dx.doi.org/10.2118/28389-MS

Lewis, A. M., \& Hughes, R. G. (2008). Production Data Analysis of Shale Gas Reservoirs. Paper SPE 116688 presented at the SPE Annual Technical Conference and Exhibition. Denver, Colorado, 21-24.

Li, S., Zhou, S. H., \& Du, J. F. (2002). Retrospect and Prospect of Enhancing Oil Recovery Technology by Gas Injection Both Aboard and Home. Petroleum Geology and Recovery Efficiency, 9(2), 1-5.

Luo, S. Q., Neal, L., Arulampalam, P., \& Ciosek, J. M. (2010). Flow Regime Analysis of Multi-stage Hydraulically-Fractured Horizontal Wells with Reciprocal Rate Derivative Function: Bakken Case Study. Paper SPE 137514 presented at the Canadian Unconventional Resources and International Petroleum Conference. Calgary, Alberta, 19-21.

Medeiros, F., Ozkan, E., \& Kazemi, H. (2008). Productivity and Drainage Area of Fractured Horizontal Wells in Tight Gas Reservoirs. SPE Reservoir Evaluation \& Engineering, 11(5), 902-911. SPE-108110-PA. http://dx.doi.org/10.2118/108110-PA

Song, B., Economides, M. J., \& Ehlig-Economides, C. A. (2009). Design of Multiple Transverse Fracture Horizontal Wells in Shale Gas Reservoirs. Paper SPE 140555 presented at the SPE Hydraulic Fracturing Technology Conference. Woodlands, TX, 24 -26.

Wang, X. D., Luo, W. J., \& Hou, X. C., et al. (2014) Transient Pressure Analysis of Multiple-fractured Horizontal Wells in Boxed Reservoirs. Petroleum Exploration and Development, 41(1), $74-78$. http://dx.doi.org/10.1016/S1876-3804(14)60008-2

Zerza, A., Tiab, D., \& Bettam, Y. (2004). Interpretation of Multiple Hydraulically Fractured Horizontal Wells; SPE 88707, presented at the $11^{\text {th }}$ Abu Dhabi International Petroleum Exhibition and Conference, Abu Dhabi, U.A.E., 10-13.

\section{Copyrights}

Copyright for this article is retained by the author(s), with first publication rights granted to the journal.

This is an open-access article distributed under the terms and conditions of the Creative Commons Attribution license (http://creativecommons.org/licenses/by/3.0/). 